\title{
Peptik ülser ve fonksiyonel dispepside ardışık tedavi ile yapılan Helicobacter pylori eradikasyonunun klinik etkisi
}

\author{
The clinical effect of Helicobacter pylori eradication with sequential therapy in patients with peptic \\ ulcer or functional dyspepsia
}

Murat SARIKAYA ${ }^{1}$, Nesibe TAŞER ${ }^{2}$, Bilal ERGÜL ${ }^{1}$, Zeynal DOĞAN ${ }^{1}$, Levent FILIIK ${ }^{1}$

Ankara Eğitim ve Araştırma Hastanesi, ${ }^{1}$ Gastroenteroloji Kliniği, ${ }^{2}$ Iç Hastalıklanı Kliniği, Ankara

\begin{abstract}
Giriş ve Amaç: Helicobacter pylori enfeksiyonu peptik ülser ve fonksiyonel dispepsi etiyolojisinde önemli rol oynamaktadır. Helicobacter pylori eradikasyonu peptik ülserli hastalarda büyük fayda sağlamasına karşın fonksiyonel dispepsili hastalarda bu yarar üzerine daha az sayıda veriler bulunmaktadır. Bu çalışmada Helicobacter pylori enfeksiyonu saptanan ülserli ve nonülser dispepsili hastalarda ardışık eradikasyon tedavisinin yararını karşlaştırmayı amaçladık. Gereç ve Yöntem: Çalışmaya total 166 hasta dahil edildi. Hastalarda Helicobacter pylori pozitifliği gastroskopik biyopsi ve hızl üreaz testi ile tespit edildi. Tüm hastalarda 12. haftada eradikasyon durumu üre nefes testi ile kontrol edildi. Semptomatik düzelme için Gastrointestinal Semptom Değerlendirme Skalası kullanıldı. Bulgular: Ülser ve fonksiyonel dispepsi gruplarının her ikisinde de ardışık tedavi ile Gastrointestinal Semptom Değerlendirme Skalası skorlarında anlamlı farklılı saptandı $(p<0,001)$ Ülser ve dispepsili hastalar karșllaştırıldığında ise ülserli hastalar lehine anlamlı farklılık saptandı $(p=0,007)$. Sonuç: Helicobacter pylori eradikasyonu hem ülserli hem de fonksiyonel dispepsili hastalarda semptomatik düzelmeyi sağlamaktadır. Bu düzelme ülserli hastalarda daha belirgin olmaktadır. Eradikasyon tedavisi hastaların yaşam kalitesinde artışa yol açarak özellikle fonksiyonel dispepsili hastaların hastaneye başvuru sıklığını ve tedavi maliyetlerini azaltacaktır.
\end{abstract}

Anahtar Kelimeler: Helicobacter pylori, ardışık eradikasyon tedavisi, fonksiyonel dispepsi, peptik ülser

\section{GİRİs ve AMAÇ}

Peptik ülser (PÜ) muskülaris mukozaya kadar uzanan gastrointestinal mukozal defektlerdir. PÜ hastalığının yıllık insidansı \%0,1 ile 0,3 arasında değişmektedir. Helicobacter pylori (H. pylori) enfeksiyonu, nonsteroidal anti-inflamatuar ilaçlar (NSAII) başta olmak üzere çeşitli ilaçlar, yaşam tarzı, genetik faktörler, ciddi fizyolojik stres ve hipersekretuvar durumlar etiyolojisinde yer almaktadır (1-4).

Dispepsi erişkin yaş grubunda en sık görülen kronik hastalıktır (5). Türkiye popülasyonunun \%28,4'ünü etkilediği gösterilmiş ve bu hastaların çoğunluğu medikal tedavi de almaktadır (6). Fonksiyonel dispepsi (FD) en az 6 ay içinde semptom başlangıcı ve son 3 ayda epigastrik ağrı ve rahatsızlık, erken doyma, postprandiyal dolgunluk hissi gibi Roma 3 kriterle-
Background and Aims: Helicobacter pylori infection plays an important role in the etiology of peptic ulcer and functional dyspepsia. Patients with peptic ulcer benefit from eradication of Helicobacter pylori, but there are fewer data related to this favorable response in patients with functional dyspepsia. In this study, we aimed to compare the benefit of sequential eradication therapy in patients with ulcer and non-ulcer dyspepsia who were diagnosed with Helicobacter pylori infection. Materials and Methods: 166 patients were included in this study. Helicobacter pylori was checked via gastroscopic biopsy and rapid urease test. In all patients, the eradication status was checked by urea breath test in the $12^{\text {th }}$ week. Gastrointestinal symptom rating scale score was used to determine symptomatic improvement. Results: In the groups of ulcer and functional dyspepsia, a significant difference was determined in gastrointestinal symptom rating scale scores with sequential therapy $(p<0,001)$. When the patients with ulcer and dyspepsia were compared, a significant difference was observed in favor of the patients with ulcer $(p=0,007)$. Conclusions: Eradication of Helicobacter pylori causes symptomatic improvement in patients with ulcer and functional dyspepsia, but this improvement is more distinct in patients with ulcer. Eradication therapy will increase the quality of life of patients and will especially reduce the frequency of application to hospital and the costs of treatment in patients with functional dyspepsia.

Keywords: Helicobacter pylori, sequential therapy, functional dyspepsia, peptic ulcer

ri ile tanımlanan fonksiyonel gastrointestinal bir hastalıktır. FD'nin nedenleri arasında gastrik motilitedeki değişiklik, genetik yatkınlık, viseral hipersensitivite, psikososyal faktörler ve $H$. pylori enfeksiyonu bulunmaktadır $(7,8)$.

H. pylori eradikasyonu PÜ ve dispepsisi olan hastalarda fayda sağlamaktadır. Bu nedenle Maastricht 4 konsensus raporunda hem duodenal hem de gastrik ülser'de eradikasyon önerilmektedir. H. pylori eradikasyonu ile ülserde \%90'dan fazla effektif iyileşme sağlanmaktadır (9). Bu çalışmada H. pylori eradikasyonunun ülserli ve nonülser dispepsili hastalarda gastrointestinal semptomlar üzerine olan etkilerini karşılaştırmayı amaçladık. 


\section{GEREÇ ve YÖNTEM}

Bu çalışma randomize tek-kör olarak dizayn edildi ve Ankara Eğitim ve Araştırma Hastanesi'nde yürütüldü. Yerel etik kurul tarafından araştırma protokolü onaylandı. Çalışma öncesinde tüm hastalardan aydınlatılmıs onam formu alındı. Ülser ve nonülser dispepsili H. pylori pozitif saptanan hastalar çalışmaya dahil edildi. Endoskopik biyopsi ve hızlı üreaz $H$. pylori testleri taramada kullanıldı. Çalışmaya total olarak 166 hasta (40 gastrik ülser, 53 duodenal ülser ve 73 dispepsi) dahil edildi. 11 hasta takip dışı kalması ve 4 hasta da yan etkiler nedeniyle çalışma dışı kaldı. Hastaların dağılımı Tablo l'de gösterilmektedir. Hastalara ardışık tedavi ( 7 gün boyunca günde iki kez $20 \mathrm{mg}$ omeprazol $+1.000 \mathrm{mg}$ amoksisilin ve takip eden 7 günde de günde iki kez $20 \mathrm{mg}$ omeprazol +500 mg metranidazol + $500 \mathrm{mg}$ klaritromisin) başlandı. H. pylori durumu 12. haftada üre-nefes testi ile kontrol edildi.

12. ayda semptomatik düzelme Gastrointestinal Semptom Değerlendirme Skalası (GSRS) kullanılarak değerlendirildi. GSRS sık görülen gastrointestinal bozuklukları değerlendirmeyi sağlayan, gastrointestinal semptomlar ve klinik deneyimlere dayanan gelişmiş bir skaladır. Skorlar bireysel skaladaki maddelerin ortalamasının alınması ile hesaplanır ve skorun artması semptomların ciddiyetini gösterir (10-12).

Çalışmaya dahil edilmeme kriterleri; pirozis veya irritabl barsak sendromu semptomlarının baskın olması, alarm semptomlarının olması, üst gastrointestinal cerrahi veya biliyer kolik, H. pylori eradikasyon tedavisi öyküsü, çalışmada kullanılan ilaçlara alerji, ciddi komorbiditeler, sigara, alkol ve ilaç bağımlılığı. 4 hafta öncesinde antibiyotik veya bizmut kullanımı, 2 hafta öncesinde proton pompa inhibitörü kullanımı da dışlama kriterleri arasında bulunmaktadır. Doğurganlık potansiyeli olan kadınlar, çalışma anketlerine cevap veremeyecek hastalar ve isteksiz veya onam veremeyecek hastalar da dışlandı.

\section{İstatistiksel Analizler}

Istatistiksel analiz SPSS istatiksel yazılımı ile yapıldı (Windows için 17.0 versiyonu; SPSS Inc, Chicago, IL, U.S.A). Degerler aritmetik ortalama \pm standart sapma olarak ifade edildi. Değişkenlerin değerlerinin normal dağılım gösterip göstermediği Kolmogorov-Smirnov testi ile belirlendi. Gruplar arası karşılaştırmalar için iki grup ortalamasının karşılaştırmasında kullanılan Mann-Whitney U Testi kullanıldı. Grup içi analizlerde ise Wilcoxon Signed Ranks testi kullanıldı. Mann-Whitney $\mathrm{U}$ ve Wilcoxon Signed Ranks testi için $\mathrm{p}<0,05$ ise aradaki farkın anlamlı olduğuna karar verildi.

\section{BULGULAR}

Çalışma hastalarında ardışık tedavi ile H. pylori eradikasyonu 120 hastada sağlanırken 31 hastada eradikasyon sağlanamadı.
Tablo 1. Hastaların demografik ve klinik karekteristikleri

\begin{tabular}{|lccc|}
\hline & Ülser (n:63) & Dispepsi (n:57) & P değeri \\
\hline Yaş & $38,1 \pm 11,9$ & $34,9 \pm 12,1$ & 0,1 \\
\hline Cinsiyet (K/E) & $40 / 23$ & $38 / 19$ & 0,7 \\
\hline GSRS Skoru (Tedavi Öncesi) & $8,8 \pm 4,3$ & $8,5 \pm 3$ & 0,9 \\
\hline GSRS Skoru (Tedavi Sonrasi) & $3,6 \pm 3,2$ & $4,6 \pm 3,0$ & 0,04 \\
\hline
\end{tabular}

GPRS: Gastrointesninal Semptom Değerlendirme Skalası

Tablo 2. Gruplar arasında ve grup içi GSRS skoru değişimi

\begin{tabular}{|lccc} 
& Mean \pm SD & $\begin{array}{c}\text { Grup İçi GSRS } \\
\text { Değişimi İçin P } \\
\text { Değeri }\end{array}$ & $\begin{array}{c}\text { Gruplararası } \\
\text { GSRS Değişimi } \\
\text { İçin P Değeri }\end{array}$ \\
\hline Ülser & $5,3 \pm 2,9$ & $<0,001$ & 0,007 \\
\hline Dispepsi & $3,8 \pm 1,9$ & $<0,001$ & 0,1 \\
\hline
\end{tabular}

GPRS: Gastrointesninal Semptom Değerlendirme Skalası

Eradikasyon oranı \%79,4 olarak tespit edildi. Tedavi gruplarındaki hastalar cinsiyet, yaş ve tedavi öncesi semptom skoru açısından benzerdi (Tablo 1). Her iki tedavi grubunda da 12 ayda anlamlı semptom düzelmesi gözlendi (her iki grupta da $\mathrm{p}<0,001)$. Gruplar karşılaştırıldığında da istatistiksel olarak ülser grubu lehine anlamlı fark saptandı (p:0,007) (Tablo 2).

\section{TARTISSMA}

H. pylori insanların \%50'sinden fazlasında gastrik mukozada kolonize olarak kronik inflmasyona yol açmaktadır (13). H. pylori FD, PÜ ve gastrointestinal sistem maligniteleri gibi pek çok hastalığın etiyolojisinde rol oynamaktadır. Duodenal ve gastrik ülserin H. pylori enfeksiyonu ile ilişkili olduğu tespit edilmiştir. Enfekte bireylerde PÜ gelişimi riski enfekte olmayan bireylere göre 3-4 kat daha fazladır. H. pylori enfeksiyonu duodenal ülserli hastaların \%90-100'ünde ve gastrik ülserli hastaların \%60-100'ünde tesbit edilmiştir. Sitotoksin üreten veya Cag A taşıyan bakteri suşları ile infekte kişilerde duodenal ülser riski daha yüksektir. H. pylori ile enfekte bireylerde PÜ riskini artıran diğer faktörler mide asit üretimi (gastrik ülser hastalığında azalan, duodenal ülserde artan), duodenum bulbusunda gastrik metaplazi varlığı, sigara kullanımı ve genetik faktörleri içermektedir. H. pylori eradikasyonu sonrası gastrik ülser rekürrens riski \%10'un altına inerken, duodenal ülserde ise bu oran yaklaşı \%0'dır (14). H. pylori eradikasyonuna yönelik pekçok tedavi protokolü uygulanmaktadır. Pek çok çalışmada ardışık tedavinin standart üçlü tedaviye üstün olduğu gösterilmiştir. Ardışık tedavide eradikasyon oranlanı coğrafik bölgelere göre değissmekle birlikte genellikle \%76 ile \%82 arasında değişmektedir (15). Sunduğumuz çalışmada ise ardışık tedavi ile eradikasyon oranını \%79,4 olarak tespit edildi. Bu sonuç literatür ile uyumlu bulunmuştur.

GSRS skorlarına dayalı yaşam kalitesi değerlendirilmesinde gerek ülserli olgular gerekse ülseri olmayan FD'li olgularda 
eradikasyonun yaşam kalitesinde anlamlı bir düzelme sağladığı görülmüştür. Her iki grubun eradikasyon sonrası GSRS skorları karşılaştırıldığında özellikle ülserli olgularda, FD'li gruba klyasla daha belirgin düzelme olduğu gözlenmiştir (Tablo 2). Bu sonuç, ülserli hastada H. pylori eradikasyonu sonucunda sadece ülser iyileşmesindeki katkısının ötesinde yaşam kalitesindeki düzelmenin vurgulanması açısından ayrıca önemlidir.

Benzer şekilde, bu çalışma FD'li hastalardaki H. pylori eradikasyonunun yaşam kalitesindeki artışın vurgulanması açı-

\section{KAYNAKLAR}

1. García Rodríguez LA, Hernández-Díaz S. Risk of uncomplicated peptic ulcer among users of aspirin and nonaspirin nonsteroidal antiinflammatory drugs. Am J Epidemiol 2004;159:23-31.

2. Kurata JH. Epidemiology: Peptic ulcer risk factors. Semin Gastrointest Dis 1993;4:2

3. Rosenstock SJ, Jørgensen T, Bonnevie O, Andersen LP. Does Helicobacter pylori infection explain all socio-economic differences in peptic ulcer incidence? Genetic and psychosocial markers for incident peptic ulcer disease in a large cohort of Danish adults. Scand J Gastroenterol 2004;39:823-9.

4. Sung JJ, Kuipers EJ, El-Serag HB. Systematic review: the global incidence and prevalence of peptic ulcer disease. Aliment Pharmacol Ther 2009;29:938-46

5. Agreus L. Natural history of dyspepsia. Gut 2002:50(Suppl 4):iv2-9.

6. Kitapçıŏlu G, Mandıracıoğlu A, Bor CC, Bor S. Overlap of symptoms of dyspepsia and gastroesophageal reflux in the community. Turk J Gastroenterol 2007;18:14-9.

7. Hernando-Harder AC, Franke A, Singer MV, Harder H. Functional dyspepsia. New pathophysiologic knowledge with therapeutic implications. Medicina (B Aires) 2007;67:379-88.

8. Mimidis K, Tack J. Pathogenesis of dyspepsia. Dig Dis 2008;26:194202. sından önemlidir. Nitekim FD'li olguların hastaneye başvuru ve tedavi süreleri açısından sağllk sistemi üzerinde belirgin yük oluşturduğu genel olarak kabul edilen bir görüştür. Bu nedenle FD'li hastalarda eradikasyon bu yönüyle de birinci basamak hekimleri tarafından da tercih edilmelidir.

FD'de ardışık eradikasyon tedavisi ile ilgili yayınlar henüz yeterli düzeye gelmemiştir. Bu çalışmanın sonuçları, eradikasyon oranlarındaki düşüklük, direnç gibi nedenlerle standart üçlü tedavi verilmeyen kişilerin tedavisinde önemli bir alternatif gibi görünmektedir.
9. Malfertheiner P, Megraud F, O'Morain CA and European Helicobacter Study Group. Management of Helicobacter pylori infection--the Maastricht IV/ Florence Consensus Report. Gut 2012;61:646-64.

10. Dimenas E, Glise H, Hallerback B, et al. Well-being and gastrointestinal symptoms among patients referred to endoscopy owing to suspected duodenal ulcer. Scand J Gastroenterol 1995;30:1046-52.

11. Svedlund J, Sjodin I, Dotevall G. GSRS-a clinical rating scale for gastrointestinal symptoms in patients with irritable bowel syndrome and peptic ulcer disease. Dig Dis Sci 1988;33:129-34.

12. Kulich KR, Madisch A, Pacini F, et al. Reliability and validity of the Gastrointestinal Symptom Rating Scale (GSRS) and Quality of Life in Reflux and Dyspepsia (QOLRAD) questionnaire in dyspepsia: a six-country study. Health Qual Life Outcomes 2008;6:12.

13. Stein M, Ruggiero P, Rappuoli R, Bagnoli F. Helicobacter pylori CagA: From pathogenic mechanisms to its use as an anti-cancer vaccine. Front Immunol 2013;4:328.

14. Kuipers EJ, Thijs JC, Festen HP. The prevalence of Helicobacter pylori in peptic ulcer disease. Aliment Pharmacol Ther 1995;9 (Suppl 2):59-69.

15. O'Connor A, Molina-Infante J, Gisbert JP, O'Morain C. Treatment of Helicobacter pylori infection 2013. Helicobacter 2013;18 (Suppl 1):58-65. 